\title{
O-GlcNAc Transferase Is Essential for Sensory Neuron Survival and Maintenance
}

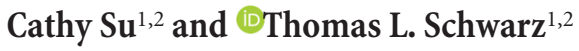 \\ ${ }^{1}$ The F.M. Kirby Neurobiology Center, Boston Children's Hospital, and 2Department of Neurobiology, Harvard Medical School, Boston MA 02115
}

$O$-GlcNAc transferase (OGT) regulates a wide range of cellular processes through the addition of the $O$-GlcNAc sugar moiety to thousands of protein substrates. Because nutrient availability affects the activity of OGT, its role has been broadly studied in metabolic tissues. OGT is enriched in the nervous system, but little is known about its importance in basic neuronal processes in vivo. Here, we show that OGT is essential for sensory neuron survival and maintenance in mice. Sensory neuron-specific knock-out of OGT results in behavioral hyposensitivity to thermal and mechanical stimuli accompanied by decreased epidermal innervation and cell-body loss in the dorsal root ganglia. These effects are observed early in postnatal development and progress as animals age. Cultured sensory neurons lacking 0GT also exhibit decreased axonal outgrowth. The effects on neuronal health in vivo are not solely due to disruption of developmental processes, because inducing OGT knock-out in the sensory neurons of adult mice results in a similar decrease in nerve fiber endings and cell bodies. Significant nerve-ending loss occurs before a decrease in cell bodies; this phenotype is indicative of axonal dieback that progresses to neuronal death. Our findings demonstrate that OGT is important in regulating axonal maintenance in the periphery and the overall health and survival of sensory neurons.

Key words: degeneration; dorsal root ganglion; 0 -GlcNAc transferase; $O$-GlcNAcylation; sensory neuron

\section{Significance Statement}

We show the importance of 0 -GlcNAc transferase (OGT) for sensory neuron health and survival in vivo. This study is the first to find that loss of OGT results in neuronal cell death. Moreover, it suggests that aberrant $O$-GlcNAc signaling can contribute to the development of neuropathy. The sensory neurons lie outside of the blood-brain barrier and therefore, compared to central neurons, may have a greater need for mechanisms of metabolic sensing and compensation. Peripheral sensory neurons in particular are subject to degeneration in diabetes. Our findings provide a foundation for understanding the role of OGT under normal physiological conditions in the peripheral nervous system. This knowledge will be important for gaining greater insight into such disease states as diabetic neuropathy.

\section{Introduction}

$O$-GlcNAcylation is a dynamic post-translational modification present on thousands of nuclear and cytoplasmic proteins (Ma and Hart, 2014). The addition of the $O$-linked $\beta$ - $N$-acetylglucosamine moiety

\footnotetext{
Received Oct. 31, 2016; revised Dec. 12, 2016; accepted Jan. 3, 2017.

Author contributions: C.S. and T.L.S. designed research; C.S. performed research; C.S. analyzed data; C.S. and T.L.S. wrote the paper.

This work was supported by the National Institutes of Health Grants R01 GM069808 (T.L.S.), F31 NS084629 (C.S.), and P30 HD18655 in support of the Children's Hospital Boston Intellectual Disabilities Research Center Cellular Imaging, Cellular Neuroscience, and Neurodevelopmental Behavioral Cores. We thank Dr. Xiaoyong Yang (Yale University) for providing Ogt-floxed mice and Dr.Clifford Woolf (Boston Children's Hospital) for providing Nav1.8-Cre and brn3a-CreER ${ }^{T 2}$ mice. We thank Drs. Anthony Hill, Takao Omura, and Nick Andrews, and Gregorz Gorski, Olusegun Babaniyi, Lala Mkhitaryan, and Catherine Ward for instruction and technical assistance. We also thank Drs. Gülçin Pekkernaz, Erica Gornstein, Bhagat Singh, Alban Latrémolière, Marcia Haigis, Clifford Woolf, and Gary Yellen for valuable discussion.

The authors declare no competing financial interests.

Correspondence should be addressed to Thomas L. Schwarz, F.M. Kirby Neurobiology Center, Boston Children's Hospital, Harvard Medical School, Boston MA 02115. E-mail: thomas.schwarz@childrens.harvard.edu.

DOI:10.1523/JNEUROSCI.3384-16.2017

Copyright $\odot 2017$ the authors $\quad 0270-6474 / 17 / 372125-12 \$ 15.00 / 0$
}

(O-GlcNAc) is catalyzed by a single enzyme called O-GlcNAc transferase (OGT; Haltiwanger et al., 1992). Through its vast array of substrates, OGT regulates a range of cellular processes, including transcription, translation, protein trafficking, protein degradation, and stress response (Hart et al., 2007; Bond and Hanover, 2015). Moreover, the levels of the donor substrate, uridine diphosphate GlcNAc, and therefore the levels of the modification, are influenced by the availability of glucose and other nutrients, allowing O-GlcNAcylation to play a key role in metabolic sensing (Zachara and Hart, 2004; Ruan et al., 2013). Several studies have demonstrated the significance of $O$-GlcNAc signaling in peripheral metabolic processes, including insulin signaling (Yang et al., 2008; Whelan et al., 2010), $\beta$-cell function (Soesanto et al., 2011; Durning et al., 2016), and gluconeogenesis (Dentin et al., 2008; Ruan et al., 2012). Recent studies have also begun to focus on the roles of OGT in neuronal populations in the context of metabolism and have identified OGT in hypothalamic neurons as a regulator of thermogenesis (Ruan et al., 2014) and feeding (Lagerlöf et al., 2016). 
Despite its relative abundance in the nervous system (Kreppel et al., 1997; Gao et al., 2001), little is known about the global function of O-GlcNAcylation in neurons. An estimated $20 \%$ of synaptosome proteins are O-GlcNAcylated (Trinidad et al., 2012), and the modification has been implicated in such processes as neurite growth (Rexach et al., 2012), axonal branching (Francisco et al., 2009), synaptic plasticity (Tallent et al., 2009), and mitochondrial trafficking (Pekkurnaz et al., 2014). Altered O-GlcNAc signaling has also been shown to play a role in neurodegenerative diseases: multiple proteins involved in Alzheimer's disease and Parkinson's disease have been shown to be $O$-GlcNAcylated, including tau, amyloid precursor protein, and $\alpha$-synuclein (Lazarus et al., 2009; Wani et al., 2016). However, because a pan-neuronal knockout of OGT in mice results in locomotor defects and postnatal mortality by day 10 , the effects of OGT loss could only be very broadly characterized (O'Donnell et al., 2004). The in vivo significance of OGT in neurons remains little understood, particularly in fundamental processes, such as development, axonal projection, and survival.

Given its role as a metabolic sensor, one neuronal population in which OGT may be important is the peripheral nervous system and, in particular, sensory neurons. These neurons have cell bodies in ganglia along the spine and project sensory axons to multiple organs in the periphery, including the skin, and central axons that enter the spinal cord (Catala and Kubis, 2013). Because the cell bodies and sensory axons lie outside of the blood-brain barrier, they may be subject to greater fluctuations in nutrient availability than central neurons (Tomlinson and Gardiner, 2008). In particular, blood glucose levels normally change significantly between fasted and fed states, and there can be even greater variations in pathological conditions, such as diabetes. Diabetic neuropathy, a common complication of diabetes, causes patients to lose proper function of their peripheral nerves and to experience such symptoms as numbness, pain, or loss of sensation starting at the extremities (Zochodne, 2008). Additionally, a recent study demonstrated that mice with OGT deleted in Schwann cells develop demyelinating peripheral neuropathy (Kim et al., 2016). Therefore, OGT function likely has great significance in the peripheral nervous system.

As a first step to understanding the role of OGT in peripheral sensory neurons, we investigated through the deletion of OGT the importance of OGT in the basic development and maintenance of sensory neurons. We show that sensory neuron-specific knock-out of OGT in mice results in functional and anatomical deficits and affects neuron maintenance and survival over time.
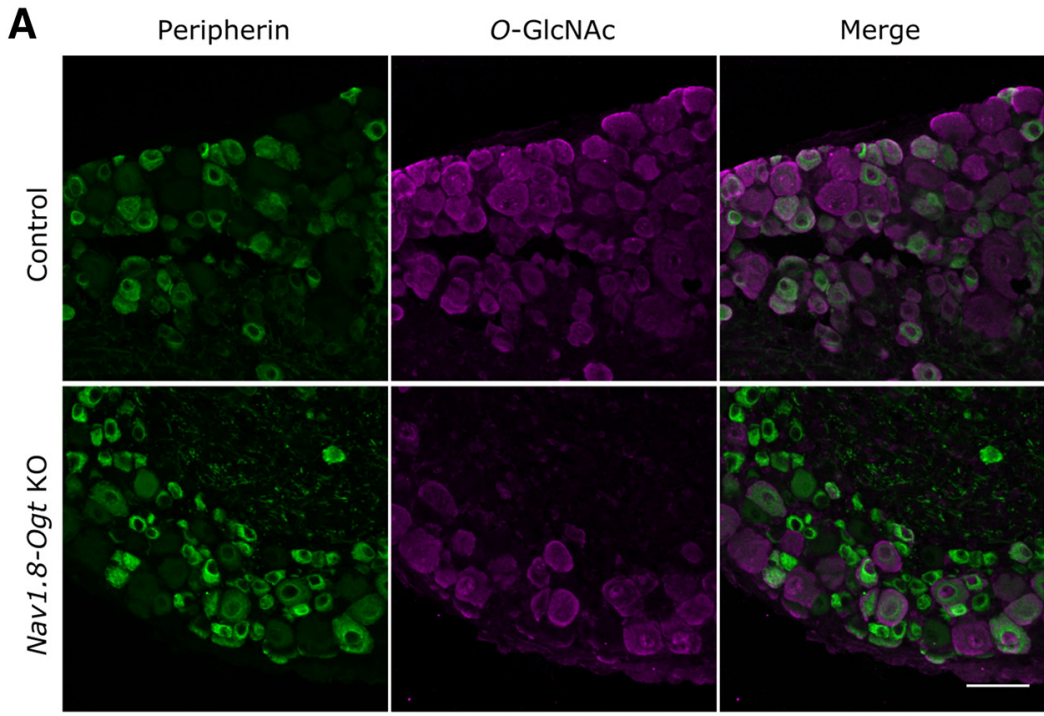

B

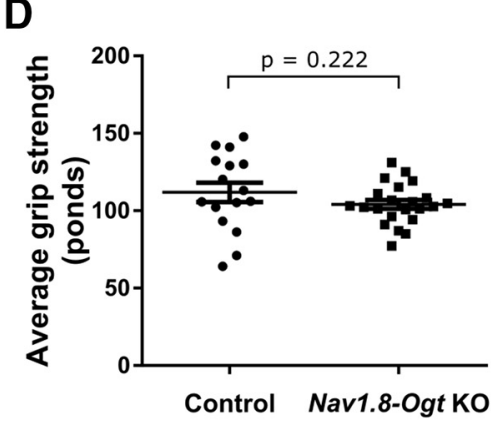

C

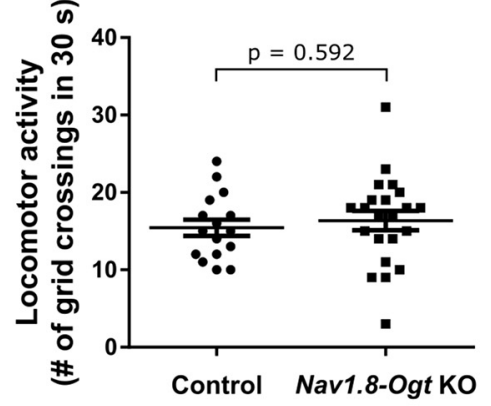

Figure 1. Nav1.8-0gt knock-out mice exhibit normal global and motor phenotypes. $\boldsymbol{A}$, Immunostaining of 0 -GICNAC (magenta) and peripherin (green) in the DRGs of control and Nav1.8-0gt knock-out (KO) mice to validate loss of 0 -GICNAcylation. The remaining 0 -GICNAc-positive cells are mostly peripherin-negative and presumably belong to the subset of sensory neurons that do not express Nav1.8. Scale bar, $50 \mu \mathrm{m}$. B, Eight-week-old mice were observed and scored in a phenotypic test battery following the modified SHIRPA protocol. $C$, Locomotor activity was measured by counting the of grid crossings of 8-week-old mice placed in an arena for 30 S. D, Grip strength was measured as the average of three consecutive readings using a grip-strength meter with 8-week-old mice. $n=16$ control and 22 Nav1.8-0gt knock-out animals, unpaired $t$ test. All values shown as mean \pm SEM.

OGT is therefore essential for sensory neuron function, axonal projection, and long-term survival.

\section{Materials and Methods}

Mice. Ogt-floxed mice on a C57BL/6 background (Shafi et al., 2000) were kindly provided by Dr. Xiaoyong Yang (Yale University). Nav1.8-Cre (Agarwal et al., 2004) and brn3a-CreER ${ }^{T 2}$ (O'Donovan et al., 2014) mice on a C57BL/6 background were kindly provided by Dr. Clifford Woolf (Boston Children's Hospital). Only male mice of the appropriate genotypes were used in the studies. All animals were housed on a $12 \mathrm{~h}$ light/ dark cycle with access to standard chow and water ad libitum. All procedures were approved by the Boston Children's Hospital Institutional Animal Care and Use Committee. 
A
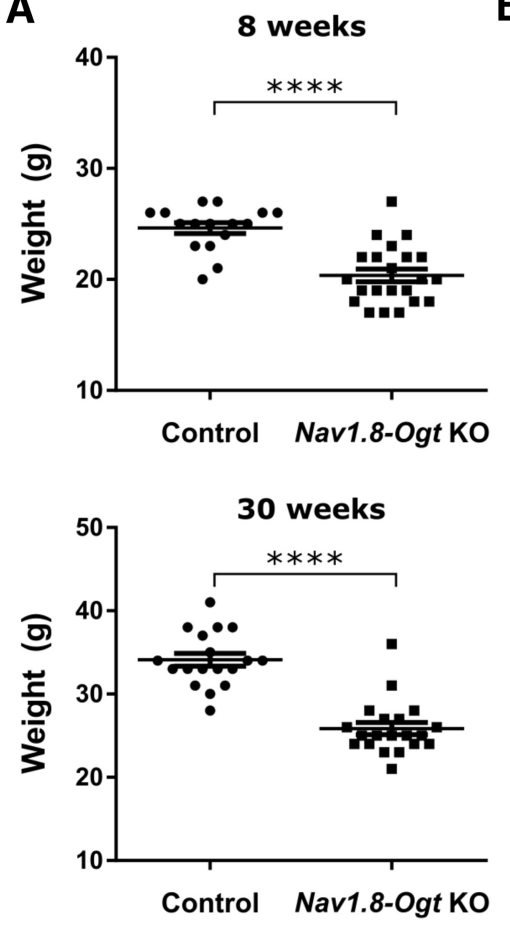

B

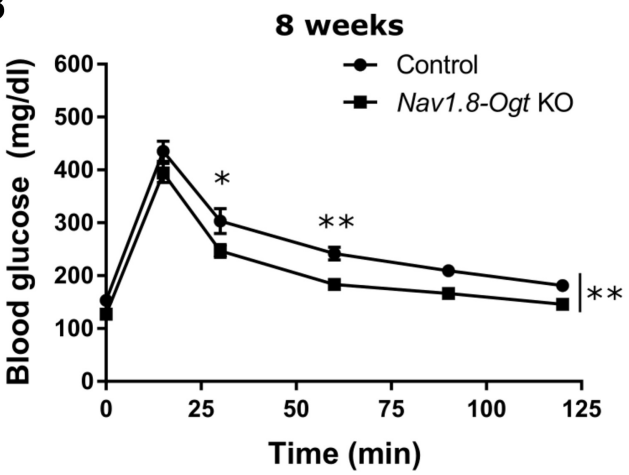

at 1:500 (Invitrogen) and anti-mouse Alexa Fluor 568 at 1:500 (Invitrogen) for $1 \mathrm{~h}$ at room temperature. Images were acquired on a Zeiss LSM 700 confocal microscope using a $25 \times$ oil objective. The numbers of $O$-GlcNAc-positive and peripherin-positive neurons were manually counted from five imaging fields per animal, and the overall proportion was calculated for each animal to represent knock-out efficiency. Peripherin is present in small-diameter DRG neurons and has significant overlap with Nav1.8 expression; therefore, most of the peripherin-positive neurons are likely also to be positive for Nav1.8-Cre in this system. Significance was calculated by unpaired Student's $t$ test.

Behavioral testing. All behavioral assays were conducted blinded as to genotype or tamoxifen treatment. Global phenotyping was assessed through a phenotypic test battery following the modified SHIRPA protocol (S: SmithKline Beecham Pharmaceuticals; H: Harwell, Medical Research Council Mouse Genome Centre and Mammalian Genetics Unit; I: Imperial College School of Medicine at St. Mary's; R: Royal London Hospital, Bartholomew's and the Royal London School of Medicine; PA: phenotype assessment). In this protocol, animals were placed in a viewing compartment and observed for the presence or absence of the following phenotypes: tremor, palpebral closure, whiskers, lacrimation, and defecation. General activity and coat appearance were also assessed. Animals were then transferred to an arena and assessed for the following phenotypes: transfer arousal, gait, tail elevation, star-

Figure 2. Nav1.8-0gt knock-out mice exhibit altered weight and glucose response. $A$, Weights of mice at 8 and 30 weeks of age. $n=16-22$ animals per genotype, unpaired $t$ test, ${ }^{* * *} p<0.0001$. B, Blood glucose was measured after intraperitoneal injection of dextrose solution ( $2 \mathrm{~g}$ of glucose $/ \mathrm{kg}$ body mass) in fasted mice at 8 and 32 weeks of age. $n=9$ animals per genotype at each age, two-way repeated-measures ANOVA with Bonferroni's correction ( $p=0.007$ at 8 weeks, $p=0.031$ at 32 weeks), ${ }^{*} p<0.05$, ${ }^{* *} p<0.01$. All values shown as mean \pm SEM.

OGT knock-out. To selectively delete OGT in sensory neurons during early development or during adulthood, female Ogt-floxed mice $\left(\right.$ Ogt $\left.{ }^{\text {loxPlloxP }}\right)$ were crossed to male Nav1.8-Cre mice $\left(\mathrm{Nav1}^{-8}\right.$-Cre $\left.^{-/+}\right)$or brn3a-CreER $R^{T 2}$ mice (brn3a-CreER ${ }^{T 2-/+}$ ). Nav1.8-Cre is expressed in most of the small-diameter sensory neurons in the dorsal root ganglia (DRGs) and trigeminal ganglia, including all nociceptors and thermoreceptive neurons, as well as a small proportion of large-diameter sensory neurons, including proprioceptive and mechanoreceptive neurons (Agarwal et al., 2004). Brn3a-CreER ${ }^{T 2}$ is expressed in all DRG neurons (O’Donovan et al., 2014). Because Ogt lies on the X chromosome, animals hemizygous for the Cre transgene and floxed Ogt allele were generated in one cross (Shafi et al., 2000). Male Nav1.8-Cre Ogt-floxed mice $\left(\mathrm{Nav1.8}-\mathrm{Cr}^{-/+} \mathrm{Ogt}{ }^{\text {loxP/Y}}\right.$ ) were identified as OGT-knock-out mice by PCR genotyping from tail samples using the following primers: $5^{\prime}$ - tgc acg ttc acc ggc atc aac g- $3^{\prime} ; 5^{\prime}$-gat gca acg agt gat gag gtt c- $3^{\prime} ; 5^{\prime}$-cat ctc tcc agc $\mathrm{ccc}$ aca aac tg- $3^{\prime}$; and $5^{\prime}$-gac gaa gca gga ggg gag agc ac- $3^{\prime}$. OGT knockout was induced in adult male brn3a-CreER ${ }^{T 2}$ Ogt-floxed mice (brn3aCreER $\left.{ }^{T 2-1+} \mathrm{Ogt}{ }^{\text {loxP/Y}}\right)$ by intraperitoneal injection of $1 \mathrm{mg}$ of tamoxifen (Sigma-Aldrich) for 5 consecutive days. Tamoxifen was freshly prepared before each experiment by suspension in sunflower oil with $5 \%$ ethanol at a concentration of $10 \mathrm{mg} / \mathrm{ml}$.

Validation of the loss of OGT was conducted by staining DRG tissue with an antibody against the $O$-GlcNAc moiety. Animals were killed, and L3-L5 lumbar DRGs were dissected, fixed in 4\% paraformaldehyde (PFA) for $1 \mathrm{~h}$ at room temperature, and cryoprotected in 30\% sucrose overnight at $4^{\circ} \mathrm{C}$. DRGs were embedded in Tissue-Tek OCT compound (Sakura Finetek) and frozen, and $20 \mu \mathrm{m}$ sections were prepared. Antigen retrieval was performed on the sections by submerging the sections in a $10 \mathrm{~mm}$ sodium citrate and $0.05 \%$ Tween 20 buffer adjusted to $\mathrm{pH} 6.0$ and heating at $90^{\circ} \mathrm{C}$ for $10 \mathrm{~min}$. After cooling, sections were blocked in $1 \%$ bovine serum albumin (BSA) and $0.1 \%$ Triton X-100 in PBS for $1 \mathrm{~h}$ at room temperature and incubated in rabbit anti-peripherin at 1:500 (Millipore) and mouse anti-O-GlcNAc at 1:200 (clone RL2, Abcam) overnight at $4^{\circ} \mathrm{C}$. Sections were then incubated in anti-rabbit Alexa Fluor 488

tle response, touch escape, and visual placing. Animals were held by the tail above the arena to assess the following phenotypes: positional passivity, paw skin color, trunk curl, and limb grasping. Additional handling of the animals was conducted to assess righting reflex, pinnal reflex, and corneal reflex. The presence or absence of biting or vocalization during the whole protocol was noted. The overall SHIRPA score was determined for each animal by scoring each observation using an arbitrary value $(0-3)$ and summing the values. Each animal was also weighed. Significance was calculated by unpaired Student's $t$ test.

Grip strength was measured using a digital grip strength meter (TSE Systems), in which each animal was positioned with its forelimbs gripping a bar and subsequently pulled away from the bar to record the maximal strength exerted. Three consecutive trials were conducted in one session and averaged for each animal. Significance was calculated by unpaired Student's $t$ test.

Locomotor activity was measured by placing the animal in a tiled arena and counting the total number of squares the animal crossed within $30 \mathrm{~s}$. A square was counted if all four paws had entered the square while the animal was moving. Significance was calculated by unpaired Student's $t$ test.

Thermosensitivity was assessed using the thermal place preference and hot-plate assays. In the thermal place preference assay, animals were placed in an arena spanning two adjacent metallic plates (Bioseb) that reciprocally oscillated between 30 and $49^{\circ} \mathrm{C}$ and video-recorded from above (Noldus EthoVision) while they were free to move over a span of $11 \mathrm{~min}$. Thermal preference was assessed for each animal by calculating and graphing the duration of time spent on each oscillating hot plate over every 30 s interval of the trial. The resulting graphs were then quantified by measuring the total area under the curve for one of the plates starting at $2 \mathrm{~min}$, in which the baseline was $15 \mathrm{~s}$ and peaks both above and below the baseline were included. Significance was calculated by unpaired Student's $t$ test.

In the hot-plate assay, animals were acclimated to an arena on top of a metallic plate (Bioseb) set at $30^{\circ} \mathrm{C}$ for $10 \mathrm{~min}$ the day before the experiment. Animals were placed within the arena on the plate set at 52, 49, or 
A
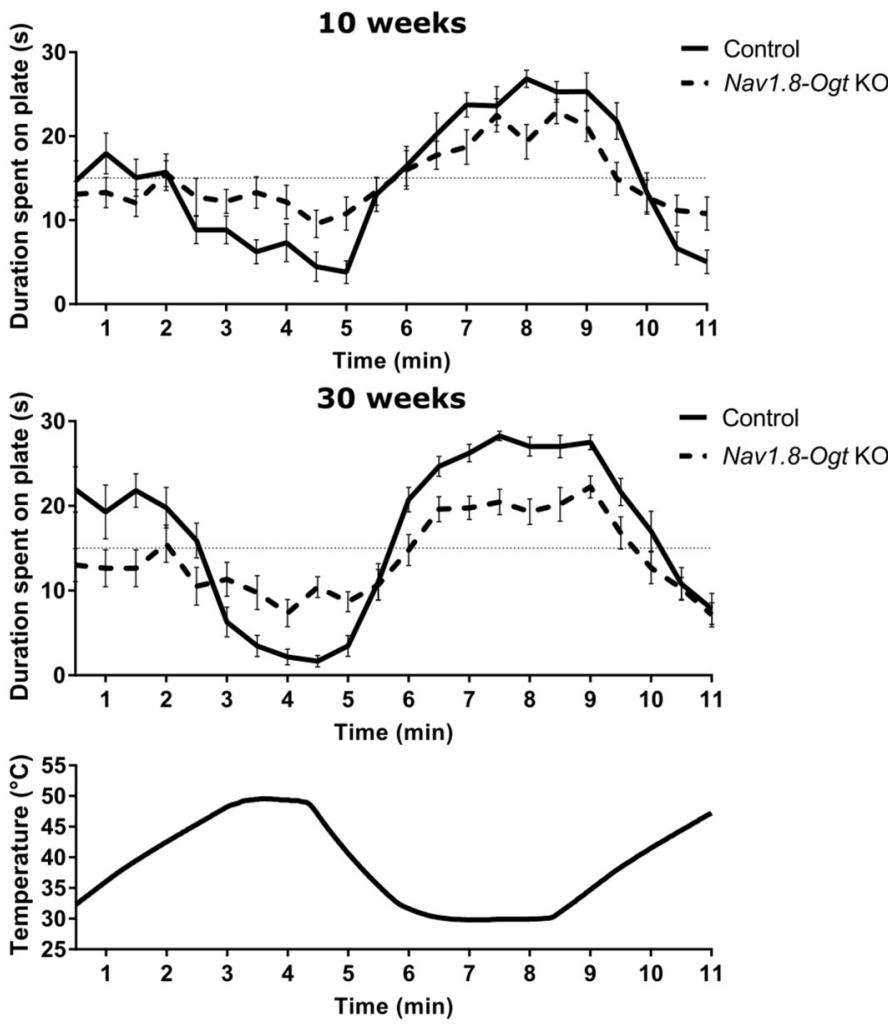

B



- Control

- Nav1.8-Ogt KO

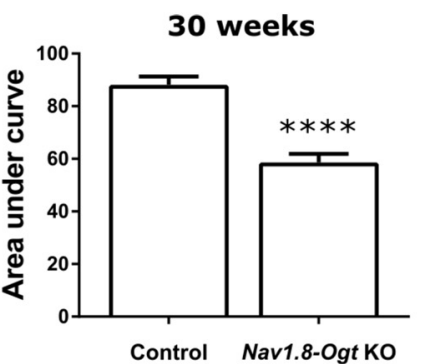

C

10 weeks

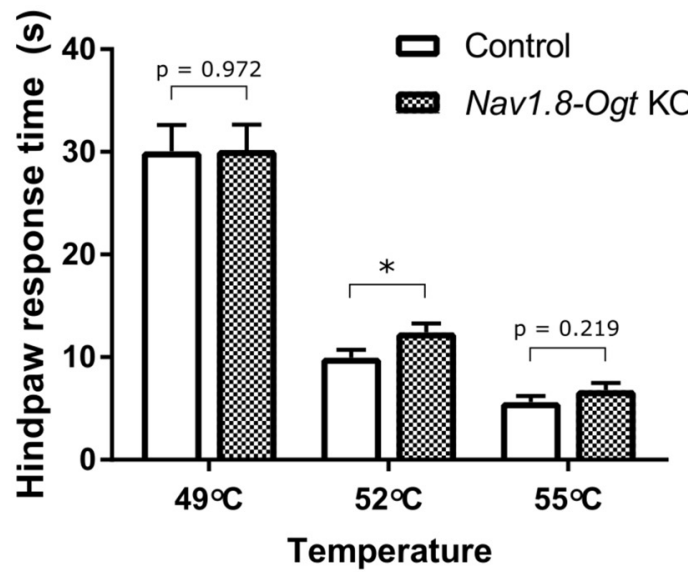

30 weeks

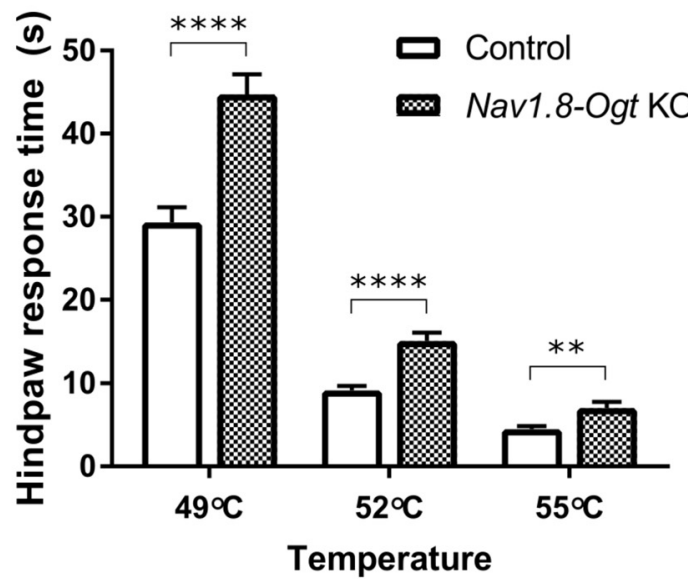

D

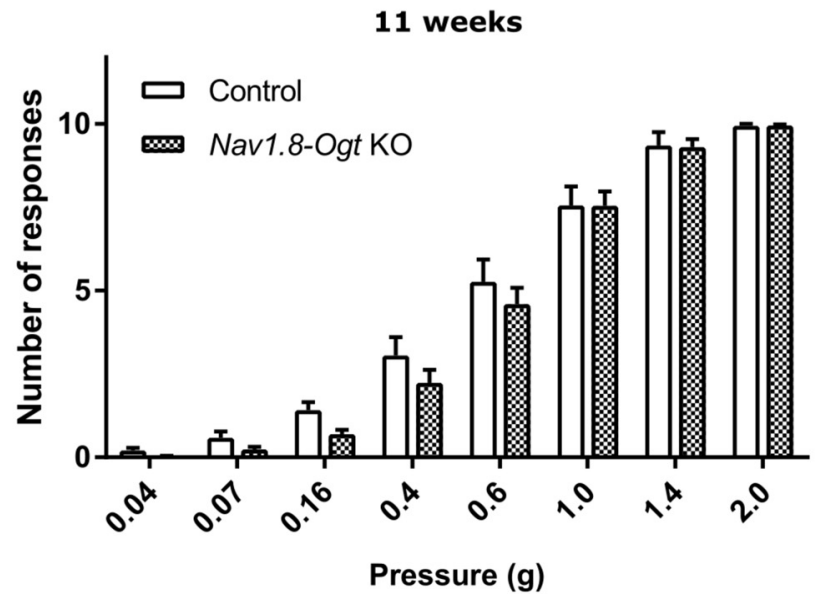

31 weeks

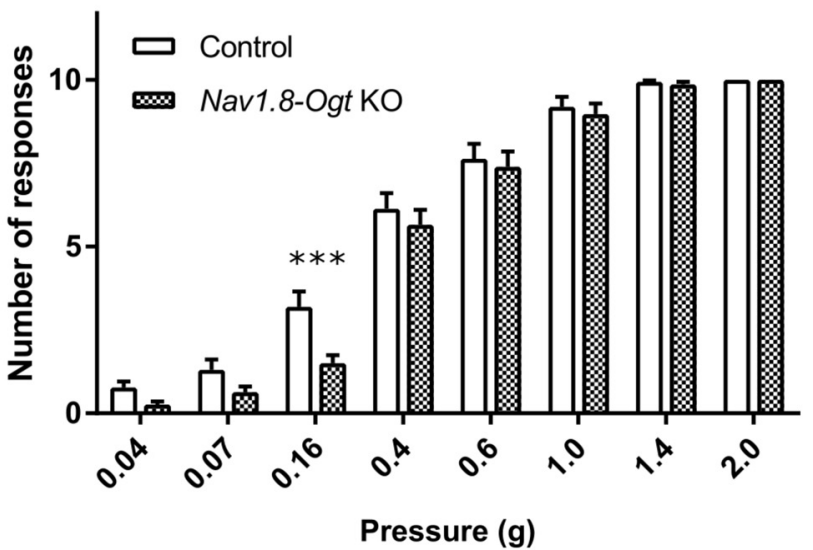

Figure 3. Nav1.8-0gt knock-out mice show behavioral deficits to thermal and mechanical stimulation. A, Average duration of time in seconds that 10-week-0ld and 30-week-old mice spent on a plate in the thermal place preference assay as the plate oscillated between the temperatures of 30 and $49^{\circ} \mathrm{C}$, as indicated by the bottom graph. A random, temperature-insensitive distribution would result in an average of $15 \mathrm{~s}$ baseline on each plate throughout the assay. $n=17-21$ animals per genotype. $\boldsymbol{B}$, The thermal place preference assay shown in $\boldsymbol{A}$ was quantified by measuring the total area between the curve and the 15 s baseline for one plate starting at 2 min. Unpaired $t$ test, ${ }^{* * *} p<0.001$, ${ }^{* * * *} p<0.0001$. C, Hot-plate assay at 10 and 30 weeks of age. The latency was measured for a hindpaw response following placement of the animal on a plate at the indicated temperatures. The assay was conducted on 3 consecutive days. $n=15-23$ animals per genotype, unpaired $t$ test, ${ }^{*} p<0.05,{ }^{* *} p<0.01,{ }^{* * * *} p<0.0001$. D, Number of hindpaw responses out of 10 applications of von Frey fiber at each corresponding pressure for 11-week-old and 31-week-old animals. Two trials were conducted over consecutive days and averaged for each animal. $n=17-23$ animals per genotype, two-way repeated-measures ANOVA (Figure legend continues.) 
$55^{\circ} \mathrm{C}$, and the amount of time for a hindpaw response, such as shaking or licking of the paw, was measured. The assay was conducted over 3 consecutive days, with one temperature tested per day. Significance was calculated by unpaired Student's $t$ test at each temperature.

Mechanosensitivity was assessed using the von Frey assay. Animals were acclimated to individual arenas on top of a raised gridded wire surface for $2 \mathrm{~h}$ each day for 2 consecutive days before testing. Mechanical stimuli were applied to the plantar surface of the hindpaw using a graded series of von Frey fibers that produced bending forces of 0.04, 0.07, 0.16, $0.4,0.6,1,1.4$, and $2 \mathrm{~g}$ (Stoelting Touch Test). Each fiber was tested 10 consecutive times in increasing order from the lowest force, and the number of paw withdrawals was recorded. Two trials were conducted over 2 consecutive days and averaged for each animal. Significance was calculated by twoway repeated-measures ANOVA with Bonferroni's correction.

Glucose tolerance test. Animals were fasted for $6 \mathrm{~h}$ during the morning and midday. Initial blood glucose levels were determined by nicking the tail vein with a razor blade, collecting a droplet of blood, and measuring the blood using a glucose meter (Accu-Chek Aviva Plus, Roche). Animals were then injected with a $20 \%$ dextrose solution (Hospira) into the intraperitoneal cavity at $2 \mathrm{~g}$ of glucose $/ \mathrm{kg}$ body mass. Blood glucose was measured at 15, 30, 60, 90, and 120 min after glucose injection. Animals that did not display a blood glucose level of $>200 \mathrm{mg} / \mathrm{dl}$ at $15 \mathrm{~min}$ after the glucose challenge were considered outliers, likely due to a technical error in the intraperitoneal injection, and were not included in the data. There were two control outliers at 8 weeks and one Nav1.8-Ogt knock-out outlier at 30 weeks. Significance was calculated by two-way repeated-measures ANOVA with Bonferroni's correction.

Epidermal innervation. Animals were killed, and footpad tissue from hindpaws or back skin were dissected, fixed in Zamboni's fixative (Stefanini et al., 1967) overnight at $4^{\circ} \mathrm{C}$, and then cryoprotected in $30 \%$ sucrose overnight at $4^{\circ} \mathrm{C}$. Samples were embedded in Tissue-Tek OCT compound (Sakura Finetek) and frozen. Sections measuring $30 \mu \mathrm{m}$ each were blocked in $1 \%$ BSA and $0.1 \%$ Triton $\mathrm{X}-100$ in PBS for $1 \mathrm{~h}$ at room temperature and incubated in rabbit anti-PGP9.5 at 1:1000 (UltraClone) or 1:500 (EnCor Biotechnology) overnight at $4^{\circ} \mathrm{C}$. Sections were then incubated in anti-rabbit Alexa Fluor 488 at 1:500 (Invitrogen) for $1 \mathrm{~h}$ at room temperature and counterstained with Hoechst for $15 \mathrm{~min}$ at room temperature. Images were acquired on a Zeiss LSM 700 confocal microscope using a $25 \times$ oil objective. The number of PGP9.5-labeled fibers in the epidermis region devoid of dermal papillae was counted over a distance of 250 $\mu \mathrm{m}$. Fiber counts from five sections were averaged for each animal. Counting was performed in a blinded manner, and significance was calculated by unpaired Student's $t$ test and one-way ANOVA with post hoc Fisher's least-significant difference test.

DRG cell-body count. Animals were killed, and L5 DRGs were dissected and processed as described above. Fourteen micrometer serial sections were prepared and incubated in rabbit anti-peripherin at 1:500 (Millipore) overnight at $4^{\circ} \mathrm{C}$ following antigen retrieval and block. Sections were then incubated in anti-rabbit Alexa Fluor 488 at 1:500 (Invitrogen) for $1 \mathrm{~h}$ at room temperature. Images were acquired on a Zeiss LSM 700 confocal microscope using a $10 \times$ air objective. The total numbers of peripherin-positive cell bodies, as determined through fluorescent labeling, and peripherin-negative cell bodies, as determined through background staining, were manually counted for every third section, or $42 \mu \mathrm{m}$. Cell-body counts from the 2 L5 DRGs were averaged for each

\footnotetext{
(Figure legend continued.) with Bonferroni's correction ( $p=0.261$ at 11 weeks, $p=0.092$ at 31 weeks), ${ }^{* * *} p<0.001$. Because strong stimuli appeared to overcome any deficits in the Nav1.8-Ogt knock-out mice, individual unpaired $t$ tests at each pressure were also conducted to assess the difference between the genotypes. For 11-week-old animals, $p=0.016$ at $0.04 \mathrm{~g}$, $p=0.070$ at $0.07 \mathrm{~g}, p=0.009$ at $0.16 \mathrm{~g}, p=0.217$ at $0.4 \mathrm{~g}, p=0.417$ at $0.6 \mathrm{~g}$, and $p=0.987$ at $1.0 \mathrm{~g}$. For 31 -week-old animals, $p=0.012$ at $0.04 \mathrm{~g}, p=0.065$ at $0.07 \mathrm{~g}, p=0.002$ at $0.16 \mathrm{~g}$, $p=0.459$ at $0.4 \mathrm{~g}, p=0.704$ at $0.6 \mathrm{~g}$, and $p=0.615$ at $1.0 \mathrm{~g}$. These comparisons suggest a loss of sensitivity to weaker stimuli at both ages. All values shown as mean \pm SEM.
}

animal. Counting was performed in a blinded manner, and significance was calculated by unpaired Student's $t$ test.

Axonal outgrowth assay. DRGs from all segments of the vertebral column were dissected from 4-week-old control (Nav1.8-Cre ${ }^{-/-} \mathrm{Ogt}{ }^{l o x P / Y}$ ) and Nav1.8-Ogt knock-out (Nav1.8-Cre $\left.e^{-/+} \mathrm{Og} t^{\operatorname{loxP} / \mathrm{Y}}\right)$ mice. Ganglia were placed in HBSS with $1 \%$ penicillin/streptomycin (pen/strep), and incubated with $5 \mathrm{mg} / \mathrm{ml}$ collagenase (Sigma-Aldrich) and $1 \mathrm{mg} / \mathrm{ml}$ dispase (Roche) for $70 \mathrm{~min}$ at $37^{\circ} \mathrm{C}$. Cells were then incubated with $0.25 \%$ trypsin for $5 \mathrm{~min}$ and washed with $0.25 \%$ trypsin inhibitor and highglucose DMEM containing 10\% fetal bovine serum and 1\% pen/strep. Cells were triturated in the presence of a DNase I inhibitor using a series of flame-polished Pasteur pipettes and centrifuged through 10\% BSA (Sigma-Aldrich) in PBS with 1\% pen/strep. The pellet was washed again in DMEM before being resuspended in Neurobasal-A medium (Life Technologies) containing 2\% B-27 supplement (Life Technologies), 1\% pen/strep, $1 \mathrm{~mm}$ L-glutamine, $50 \mathrm{ng} / \mathrm{ml}$ NGF (Life Technologies), and 2 $\mathrm{ng} / \mathrm{ml}$ GDNF (Sigma-Aldrich). Cells were plated onto $12 \mathrm{~mm}$ German glass coverslips (Bellco Glass) coated with $100 \mu \mathrm{g} / \mathrm{ml}$ poly-D-lysine (Sigma-Aldrich) and $10 \mu \mathrm{g} / \mathrm{ml}$ laminin (Life Technologies) and grown in 24-well tissue culture plates (Corning) at $37^{\circ} \mathrm{C}$ and $5 \% \mathrm{CO}_{2}$.

Twelve hours after plating, cells were fixed in 4\% PFA for $10 \mathrm{~min}$ and incubated in rabbit anti- $\beta$-tubulin III at 1:2000 (clone TUJ1 1-15-79, Covance) and mouse anti-O-GlcNAc at 1:200 (clone RL2, Abcam) in 1\% BSA, $15 \%$ goat serum, and $0.1 \%$ Triton X-100 in PBS for $1 \mathrm{~h}$ at room temperature. Cells were then incubated in anti-rabbit Alexa Fluor 488 at 1:500 (Invitrogen) and anti-mouse Alexa Fluor 568 at 1:500 (Invitrogen) for $1 \mathrm{~h}$ at room temperature. Images were acquired on a Zeiss LSM 700 confocal microscope using a $25 \times$ oil objective. Axonal outgrowth of individual neurons was quantified using Sholl analysis in ImageJ, in which the total number of neurite crossings was counted at increasing intervals of $50 \mu \mathrm{m}$ from the soma center as designated by concentric circles, starting at $25 \mu \mathrm{m}$ from the center. To exclude dying cells, only neurons with visible axons were included. Cell-body diameters and longest neurite lengths were measured in ImageJ. Significance was calculated by unpaired Student's $t$ test and two-way repeated-measures ANOVA with Bonferroni's correction.

\section{Results}

\section{Nav1.8-Ogt knock-out mice are overtly healthy but exhibit altered weight and glucose tolerance}

Pan-neuronal loss of OGT has previously demonstrated an essential neuronal role of OGT for the viability of the animals (O'Donnell et al., 2004), but due to their short lifespan, little is understood about the characteristics of neurons lacking OGT. To investigate the role of OGT in the ability of neurons to survive, project axons, and properly function in vivo, we used the Nav1.8Cre driver to selectively delete OGT in a major subset of DRG sensory neurons. These neurons relay sensory input from the skin and other peripheral organs to the CNS (Agarwal et al., 2004). Nav1.8 is a voltage-gated sodium channel expressed in most DRG neurons with C fibers. The Nav1.8-Cre-expressing neurons include peptidergic and nonpeptidergic nociceptors involved in sensing noxious thermal stimuli. Nav1.8-Cre-expressing neurons also include a percentage of those with A fibers, which are involved in sensing mechanical stimuli (Shields et al., 2012). We hypothesized that the knock-out of OGT in only this subset of neurons would result in viable animals and allow for a more comprehensive characterization of the effects of OGT loss.

Nav1.8-Ogt knock-out mice (Nav1.8-Cre ${ }^{-/+} \mathrm{Ogt} t^{\text {loxP/Y }}$ ) were born at an expected rate and developed normally alongside their littermate controls. Loss of OGT was assessed in 4-week-old mice by immunostaining for the $O$-GlcNAc modification and peripherin (Fig. 1A). Peripherin is an intermediate filament expressed in smalldiameter DRG neurons with $\mathrm{C}$ fibers and has significant overlap with Nav1.8 expression: $\sim 90 \%$ of peripherin-positive neurons contain Nav1.8 and conversely $\sim 60 \%$ of Nav1.8-positive cells contain 
peripherin (Shields et al., 2012). Therefore, we used peripherin staining to approximately distinguish cells that would most likely be Nav1.8-positive and therefore OGT-negative in our system. We observed the presence of $\mathrm{O}$-GlcNAc in only $23.7 \pm$ $3.4 \%$ of peripherin-positive DRG neuron cell bodies in Nav1.8-Ogt knock-out tissue (Nav1.8-Cre $e^{-/+} \mathrm{Ogt} t^{\text {loxP/Y}}$ ) as opposed to $94.4 \pm 0.3 \%$ of peripherin-positive cell bodies in control tissue (Nav1.8-Cre $e^{-/-} \mathrm{Og} t^{\operatorname{lox} P / Y}$; $n=3$ animals per genotype, 5 sections per animal, $p<0.0001$ by unpaired $t$ test) and thus achieved knock-out in the large majority of small-diameter DRG sensory neurons.

A global phenotype was assessed at 8 weeks of age using the modified SHIRPA protocol, in which animals were scored for a range of morphological and behavioral phenotypes (see Materials and Methods), and no significant differences were observed between Nav1.8-Ogt knock-out and control mice (Fig. 1B). Nav1.8-Ogt knock-out mice also displayed normal locomotor activity and forelimb grip strength (Fig. 1C,D). Overall, the knock-out mice were viable up to at least 1 year of age, the longest length of time they were kept before being killed, and no unexpected deaths were observed. Therefore, loss of OGT in sensory neurons does not affect the global development and behavior of mice and can serve as an appropriate system to further investigate its effects in neurons.

The one global morphological phenotype that was observed, however, was that Nav1.8-Ogt knock-out mice weighed less than their littermate controls, as measured at either 8 or 30 weeks of age (Fig. $2 A)$. To probe whether this reflects differences in metabolism, we performed an intraperitoneal glucose tolerance test on mice at 8 and 32 weeks of age. Nav1.8-Ogt knock-out mice consistently exhibited increased glucose tolerance, as indicated by lower blood glucose levels compared with control mice at 30, 60, 90, and $120 \mathrm{~min}$ after a glucose challenge (Fig. 2B). Together, these data suggest that loss of OGT in sensory neurons could lead to altered metabolic processes in mice.

Nav1.8-Ogt knock-out mice show behavioral deficits in thermal and mechanical sensitivity

To assess the behavioral consequences of OGT knock-out in sensory neurons, we conducted assays aimed at testing sensitivity to thermal and mechanical stimuli. At 10 weeks of age, Nav1.8-Ogt knock-out mice consistently exhibited a significant difference in response in the thermal place preference assay. This assay pairs a $30^{\circ} \mathrm{C}$ plate with one at $49^{\circ} \mathrm{C}$, a temperature that normally evokes an aversive behavior. Whereas

B

C
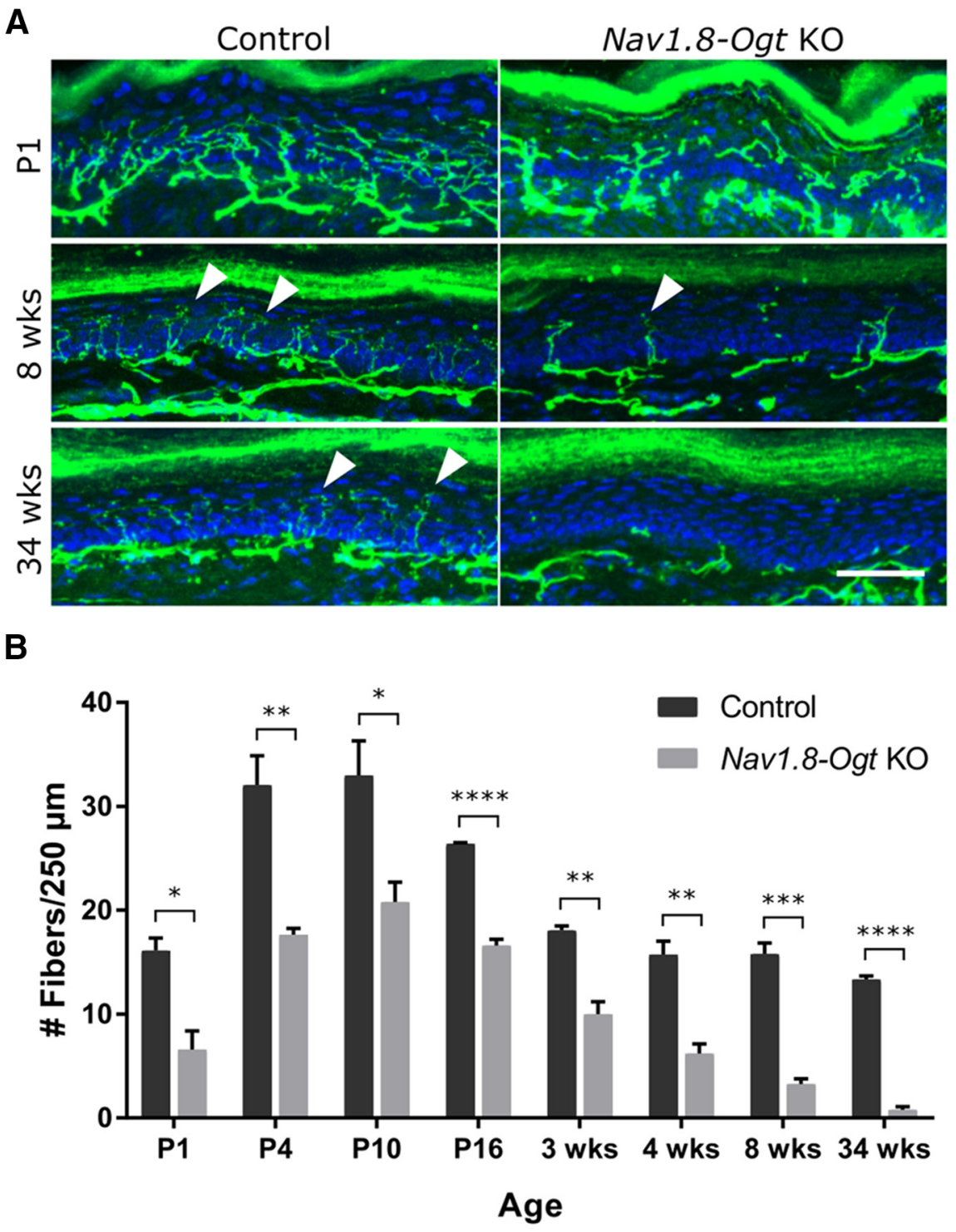
Control Nav1.8-Ogt KO

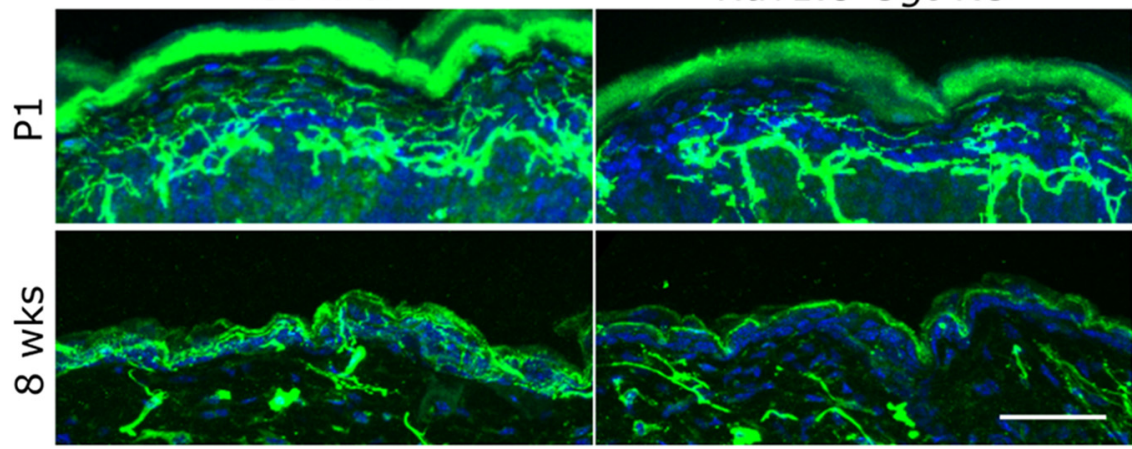

Figure 4. Decreased epidermal innervation in Nav1.8-0gt knock-out mice. A, PGP9.5 immunostaining (green) to visualize nerve fibers (white arrowheads) and Hoechst staining (blue) to visualize the keratinocyte layer in glabrous hindpaw skin at $1 \mathrm{~d}, 8$ weeks, and 34 weeks of age. Scale bar, $50 \mu \mathrm{m}$. B, Quantification of fiber number per $250 \mu \mathrm{m}$ of epidermal length. $n=3$ animals per genotype at each age (5 sections per animal), unpaired $t$ test, ${ }^{*} p<0.05,{ }^{* *} p<0.01,{ }^{* * *} p<0.001,{ }^{* * * *} p<0.0001$. All values shown as mean \pm SEM. C, Hairy back skin, immunostained as in $A$, at $1 \mathrm{~d}$ and 8 weeks of age. Scale bar, $20 \mu \mathrm{m}$.

the control animals had a strong preference for the $30^{\circ} \mathrm{C}$ plate over the adjacent $49^{\circ} \mathrm{C}$ plate, knock-out animals spent on average more time on the hotter plate than control animals. This hyposensitivity to the changes in plate temperature is visualized by a 
A
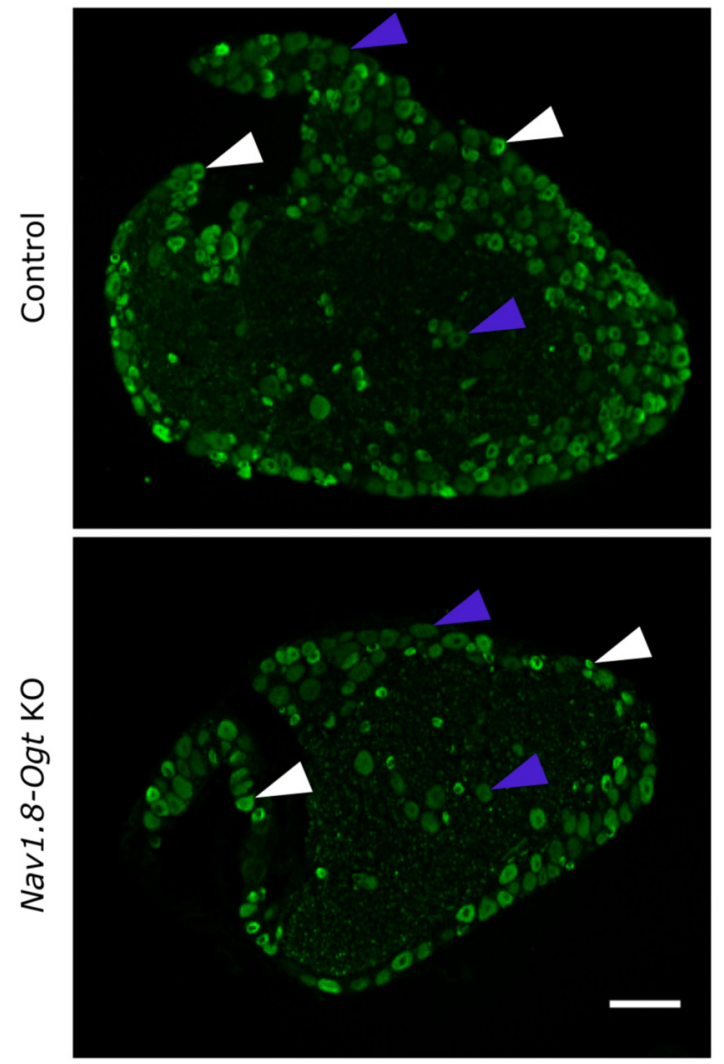

B
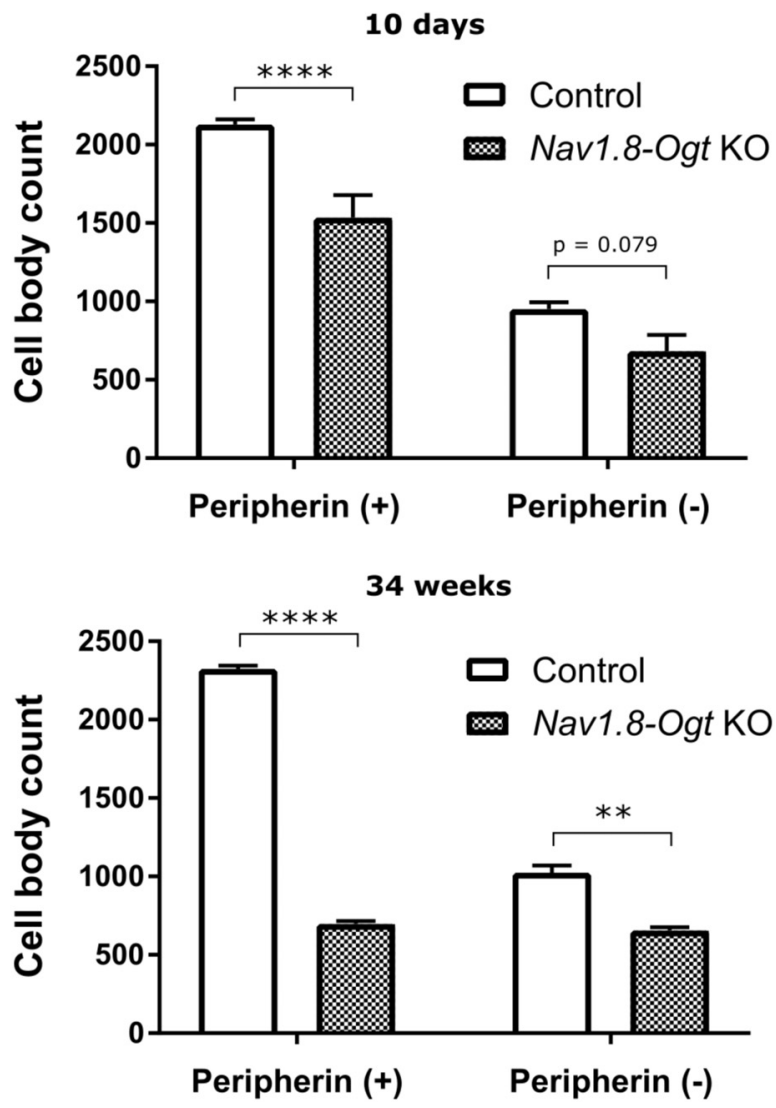

Figure 5. Loss of peripherin-expressing neuronal cell bodies in Nav1.8-0gt knock-out DRGs. A, Immunostaining of L5 DRGs from 34-week-old mice with anti-peripherin (green) to visualize peripherin-positive (white arrowheads) and peripherin-negative (purple arrowheads) decrease in amplitude of the curve representing the average duration of time spent on each plate. This appeared to be slightly more severe at 30 weeks of age (Fig. $3 A, B$ ). In the hot-plate assay, 10-week-old Nav1.8-Ogt knock-out mice exhibited slower hindpaw responses when placed on a $52^{\circ} \mathrm{C}$ plate, but not on 49 or $55^{\circ} \mathrm{C}$ plates. This increased response time was more pronounced as the animals aged, and by 30 weeks of age, knock-out mice were taking $>50 \%$ longer to respond than control mice at all three temperatures (Fig. 3C).

The von Frey assay was conducted as a test of hindpaw mechanical sensitivity. At 11 weeks of age, Nav1.8-Ogt knock-out mice exhibited largely normal responses to punctate forces compared with control mice, though slight decreases in the numbers of responses were observed at forces ranging from 0.16 to $0.6 \mathrm{~g}$. At forces of $\geq 1.0 \mathrm{~g}$, both knock-out and control mice were responsive to the fibers, whereas at forces of $<0.07 \mathrm{~g}$ the mice were equally insensitive to the fibers. At 31 weeks of age, both mutant and control mice appeared to be more sensitive to the von Frey fibers. Knock-out mice exhibited slightly fewer responses to the forces ranging from 0.04 to $0.16 \mathrm{~g}$, and the effect was statistically significant at $0.16 \mathrm{~g}$, with knock-out mice responding less than half as often as control mice (Fig. 3D).

Altogether, the data indicate a clear hyposensitivity to thermal stimuli and a mild hyposensitivity to mechanical stimuli in Nav1.8-Ogt knock-out mice. This demonstrates that loss of OGT results in functional deficits observed at the behavioral level in mice and that its effects can worsen with age.

\section{Nav1.8-Ogt knock-out mice lose epidermal innervation and DRG cell bodies}

Sensory inputs relaying thermal and mechanical information originate in free nerve endings in the skin. To understand the cause of the behavioral deficits, we examined the small fiber innervation of hindpaw epidermis from control and Nav1.8-Ogt knock-out mice. Epidermal innervation was severely reduced already at 8 weeks of age in the knock-out animals (Fig. 4A), despite the relatively mild behavioral effects seen at that age. We therefore examined the innervation throughout postnatal development and as the animals aged. In control mice, the density of epidermal innervation increases for several days after birth, and is maximal between postnatal days (P) 4 and P10. The density of innervation then declines gradually to reach stable adult levels by 3 weeks of age (Fig. 4B). Nav1.8-Ogt knock-out mice had consistently fewer nerve fiber endings in the skin already at P1 (Fig. $4 A, B)$. Although this innervation increased between $\mathrm{P} 1$ and $\mathrm{P} 10$, there remained $40-60 \%$ fewer nerve fibers/ $\mu \mathrm{m}$ of skin in the knock-out animals than in the controls. After 3 weeks of age, when the number of nerve fibers in control animals had stabilized, innervation continued to decline in the knock-out mice until at 34 weeks of age almost no fibers remained in the skin. A similar phenomenon was observed in hairy skin from the back (Fig. 4C). These results suggest that the decrease in sensitivity is due to a progressive degeneration of epidermal nerve endings rather than intact but dysfunctional nerves.

To determine whether this axonal degeneration is accompanied by loss of cell bodies, we manually counted them in serial

neuronal cell bodies. Scale bar, $100 \mu \mathrm{m}$. $\boldsymbol{B}$, Cell bodies were counted every $42 \mu \mathrm{m}$ through serially sectioned L5 DRGs from 10-d-old and 34-week-old mice. $n=3$ animals per genotype (2 DRGs from each animal), unpaired $t$ test, ${ }^{* *} p<0.01,{ }^{* * *} p<0.0001$. All values shown as mean \pm SEM. 
sections immunostained for peripherin from L5 DRGs of control and Nav1.8-Ogt knock-out mice. Brightly fluorescent peripherin-positive cells were selected as likely to represent small-diameter neurons and therefore much of the Nav1.8expressing population targeted for loss of OGT. Cell bodies that displayed weak background fluorescence were analyzed separately as peripherin-negative cells. At P10, there were fewer peripherin-positive cell bodies in DRGs from Nav1.8-Ogt knock-out animals than in controls and a less significant decrease in peripherinnegative cell bodies. At 34 weeks of age, many more cell bodies, and particularly the peripherin-positive population, appeared to have been lost (Fig. $5 A, B$ ). The smaller effect on peripherin-negative neurons can be attributed to the imperfect proxy of peripherin as a marker for Nav1.8-positive neurons; the expression pattern of Nav1.8-Cre includes a fraction of large-diameter neurons as well (Agarwal et al., 2004). These findings demonstrate that OGT is not only critical for epidermal innervation but also for neuronal survival.

\section{OGT-knock-out neurons exhibit axonal outgrowth deficits in culture}

The loss of skin innervation and cell bodies in Nav1.8-Ogt knock-out animals prompted us to examine knock-out neurons in vitro to assess their morphology and survival. DRG neurons were dissected from 4-week-old control and Nav1.8-Ogt knockout mice, sparsely plated, and cultured for $12 \mathrm{~h}$. Axons of individual neurons were visualized with $\beta$-tubulin III immunostaining, and OGT-knock-out neurons were identified by the absence of $O$-GlcNAc immunostaining (Fig. 6A). Although the extent of axonal outgrowth varied considerably for each genotype, neurons lacking OGT had on average fewer neurites (Fig. $6 B)$. To determine whether only a subset of the neuron population was contributing to this effect, the data from large ( $>30 \mu \mathrm{m}$ soma diameter) and small ( $\leq 30 \mu \mathrm{m}$ soma diameter) neurons were analyzed separately. A significant difference in axonal outgrowth was observed for both cell types, though the decrease was more significant in the larger cells, perhaps because they had more neurites to lose (data not shown). Longest neurite length was also measured, and OGT-knock-out neurons on average were shorter (Fig. $6 C$ ). These results suggest an effect of OGT on axonal growth and branching, although the selective loss of a subset of fast-growing, highly branched sensory neurons is also a possibility.

Loss of epidermal innervation and cell bodies occurs independently of developmental processes

The Nav1.8-Ogt knock-out mouse revealed that loss of OGT decreases epidermal innervation and DRG cell bodies. These effects were observed as early as P1 and, while they appeared to progress, it was unclear whether developmental defects were the primary cause of the later phenotypes. We therefore turned to a tamoxifen-inducible Cre driver, brn $3 a-C r e E R^{T 2}$, to distinguish the effects of OGT loss on neuronal development and maintenance (O'Donovan et al., 2014). Brn3a is a transcription factor expressed in all DRG sensory neurons and, through the inducible system, we deleted OGT in adult mice. Cre expression was induced at 7 weeks of age with tamoxifen injections. Two weeks later, loss of OGT was evaluated by $O$-GlcNAc immunostaining. O-GlcNAc immunoreactivity was present in $46.7 \pm 6.2 \%$ of peripherin-positive DRG neuron cell bodies in brn3a-Ogt knockout ganglia (tamoxifen-treated brn3a-CreER ${ }^{T 2-/+} \mathrm{Og} t^{\text {loxP/Y }}$ ) as opposed to $94.2 \pm 1.5 \%$ of peripherin-positive cell bodies in control ganglia (vehicle-treated brn3a-CreER $R^{T 2-/+} \mathrm{Ogt}{ }^{\text {loxP/Y }} ; n=5$ animals per genotype, 5 sections per animal, $p<0.0001$ by unpaired $t$ test). Thus, although most peripherin-positive DRG neurons had lost 


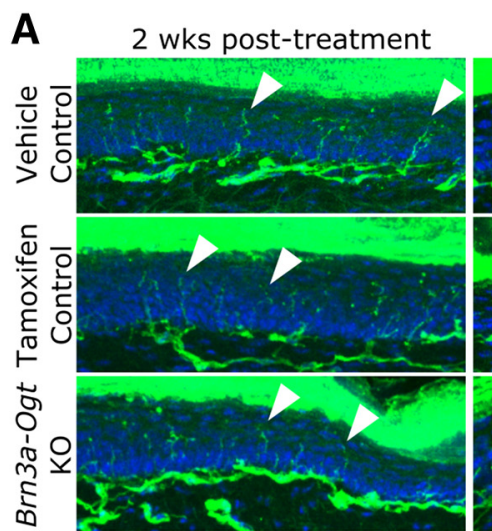

B

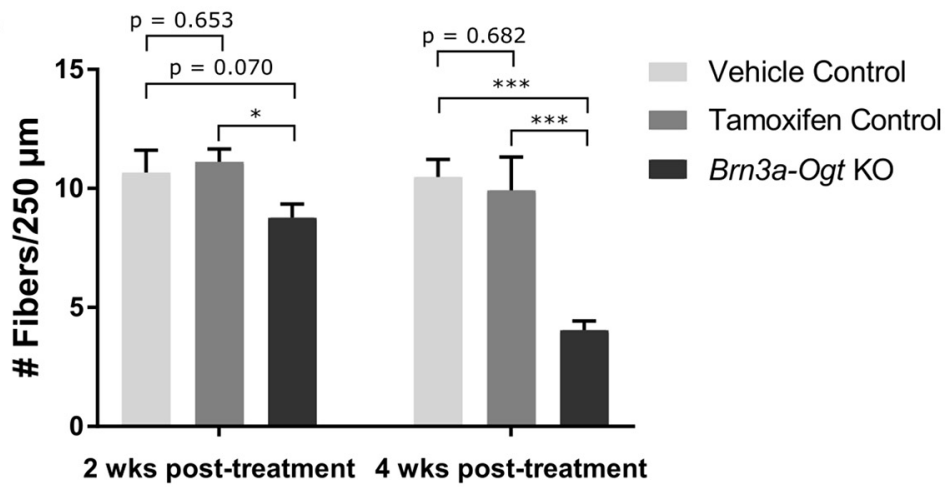

$\mathbf{E}$

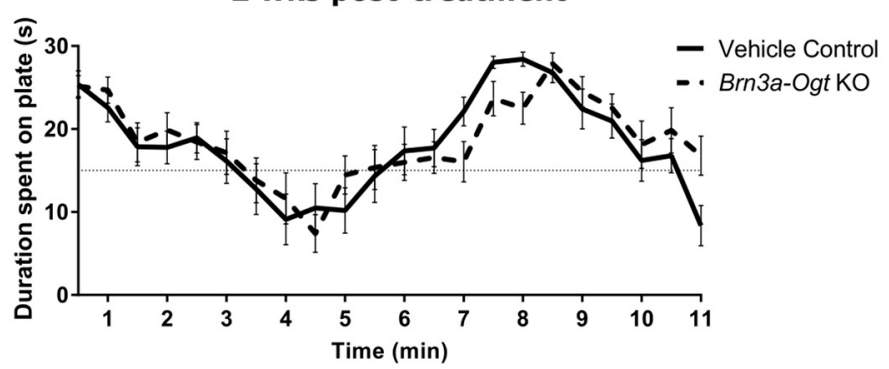

4 wks post-treatment
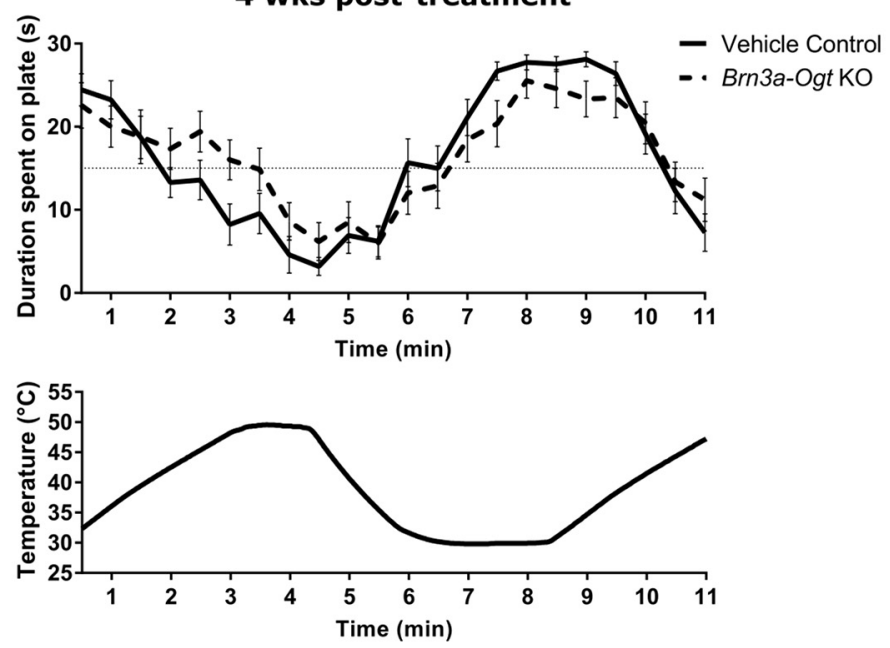

C
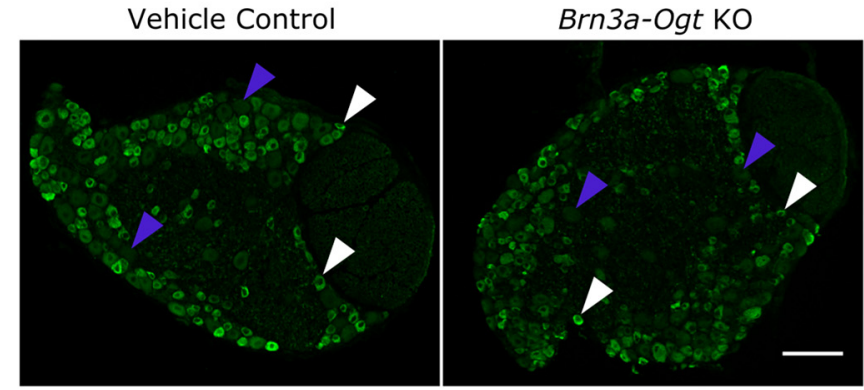

D

2 wks post-treatment

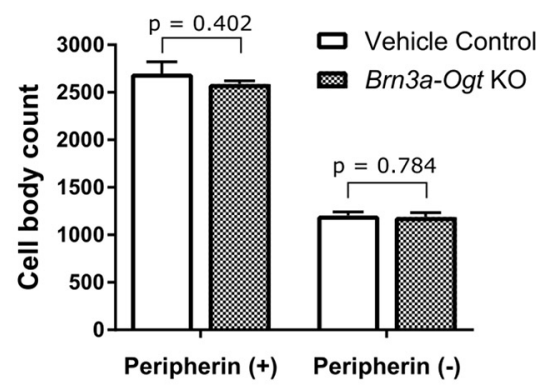

4 wks post-treatment

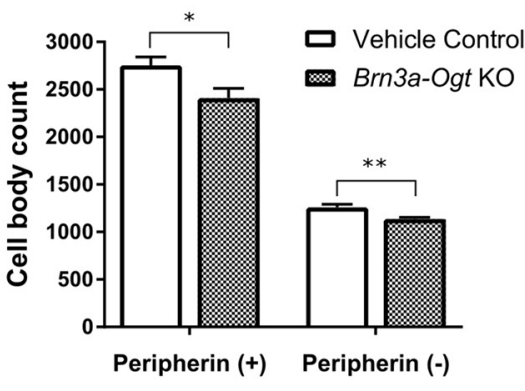

$\mathbf{F}$

2 wks post-treatment

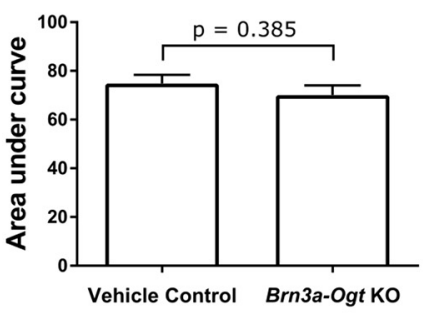

4 wks post-treatment

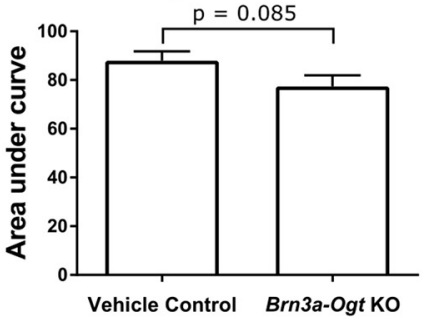

Figure 7. OGT knock-out in adult animals causes loss of epidermal innervation and DRG cell bodies. A, PGP9.5 immunostaining (green) to visualize nerve fibers (white arrowheads) and Hoechst staining (blue) to visualize the keratinocyte layer in glabrous hindpaw skin 2 and 4 weeks after either vehicle or tamoxifen injection to induce $0 \mathrm{GT}$ knock-out in adult brn3a-0gt mice. Vehicle control and brn3a-Ogt knock-out mice were of the genotype brn3a-CreER $R^{T 2-/+} O g t^{10 x P / Y}$ and the tamoxifen controls were of the genotype brn3a-CreER ${ }^{T 2-/-}$ Ogt ${ }^{\text {loxP/Y }}$. Scale bar, $50 \mu \mathrm{m}$. B, Quantification of fiber number per $250 \mu \mathrm{m}$ of epidermal length for genotypes and injections as in $A . n=6-7$ animals per condition at 2 weeks and 5 animals per condition at 4 weeks $(5$ sections per animal), one-way ANOVA with post hoc Fisher's least-significant difference test ( $p=0.055$ at 2 weeks, $p=0.001$ at 4 weeks), ${ }^{*} p<0.05,{ }^{* * *} p<0.001$. C, Immunostaining (Figure legend continues.) 
OGT, the inducible Cre driver was not as penetrant as the Nav1.8Cre driver in the knock-out mice.

As with the Nav1.8-Ogt knock-out mice, we examined epidermal innervation, cell-body count, and thermal sensitivity in brn3a-Ogt knock-out mice (tamoxifen-treated brn3a-CreER ${ }^{T 2-/+} O g t^{\text {loxP/Y }}$ ) to determine the consequences of OGT loss in adult sensory neurons. At 2 weeks after treatment, there was a slight decrease in the number of nerve fibers in hindpaw epidermis from brn3a-Ogt knock-out animals compared with that of vehicle control animals (vehicletreated $b r n 3 a-C r e E R^{T 2-/+} O g t^{l o x P / Y}$ ) and tamoxifen control animals (tamoxifen-treated brn3a-CreER ${ }^{T 2-1-} \mathrm{Ogt}{ }^{\text {loxP/Y}}$; Fig. $7 A, B$ ), but no significant difference in L5 DRG cell-body counts (Fig. 7C,D) or thermal place preference behavior (Fig. $7 E, F$ ). At 4 weeks after treatment, there was a much larger decrease in epidermal innervation, with $60 \%$ fewer fibers in brn3a-Ogt knock-out animals than in control animals (Fig. $7 A, B$ ). There were also fewer L5 DRG cell bodies in the mice lacking OGT (Fig. 7C,D). These mice still exhibited normal to mildly hyposensitive thermal place preference behavior (Fig. $7 E, F$ ). Because OGT was deleted when the sensory neurons would have been fully developed and would have innervated their peripheral targets, these results demonstrate that OGT has an important role in the maintenance and survival of adult neurons. They also suggest that the loss of OGT first affects the axons in the periphery and causes loss of the cell body subsequent to the axonal degeneration.

\section{Discussion}

O-GlcNAcylation is a post-translational modification that broadly modulates cellular processes as metabolic conditions vary (Bond and Hanover, 2015). Previous studies examined the effects of complete neuronal loss of OGT, whereupon the early death of the mice precluded detailed analysis (O'Donnell et al., 2004). Other studies have deleted OGT in a specific neuronal subpopulation to investigate a particular metabolic function (Ruan et al., 2014; Lagerlöf et al., 2016). Here, we examined the effects of OGT knock-out in peripheral sensory neurons to gain a better understanding of the importance of OGT in fundamental neuronal processes, such as axonal projection and long-term maintenance and survival. We found that loss of OGT in a subset of sensory neurons decreased skin innervation and DRG cell bodies early in postnatal development. These phenotypes worsened with age and manifested in functional deficits in thermal and mechanical sensation. These phenotypes were not solely due to disruption of developmental processes, as knock-out of OGT in adult mice also decreased skin innervation and cell-body counts.

Major consequences of OGT loss in sensory neurons are perhaps unsurprising given the number of protein substrates that are

\section{$\leftarrow$}

(Figure legend continued.) of L5 DRGs from mice 4 weeks after tamoxifen treatment with anti-peripherin (green) to visualize peripherin-positive (white arrowheads) and peripherinnegative (purple arrowheads) neuronal cell bodies. Scale bar, $100 \mu \mathrm{m}$. $\boldsymbol{D}$, Cell bodies were counted every $42 \mu \mathrm{m}$ through serially sectioned L 5 DRGs from mice 2 and 4 weeks after treatment. $n=5$ animals per condition ( $2 \mathrm{DRGs}$ from each animal), unpaired $t$ test, ${ }^{*} p<0.05$, ${ }^{* *} p<0.01$. $E$, Average duration of time in seconds that mice 2 and 4 weeks after treatment spent on a plate in the thermal place preference assay as the plate oscillated between the temperatures of 30 and $49^{\circ} \mathrm{C}$, as indicated by the bottom graph. A random, temperatureinsensitive distribution would result in an average of 15 s baseline on each plate throughout the assay. $n=13-15$ animals per genotype. $\boldsymbol{F}$, The thermal place preference assay shown in $\boldsymbol{E}$ was quantified by measuring the total area between the curve and the $15 \mathrm{~s}$ baseline for one plate starting at 2 min. Unpaired $t$ test. All values shown as mean \pm SEM.
O-GlcNAcylated in a cell. For the same reason, it is also difficult to speculate on the particular causes of the axonal degeneration and cell death. Proteomic analysis of mouse synaptosomes revealed an estimated $20 \%$ of synaptosome proteins to be $O$-GlcNAcylated, including several vesicular transport proteins, cytoskeletal proteins, and transcriptional regulators (Trinidad et al., 2012). Proteomic analysis of adult rat sciatic nerve also identified $>100 \mathrm{O}$-GlcNAcylated proteins, with an enrichment in focal adhesion and MAPK signaling pathways (Kim et al., 2016). Additionally, OGT regulates axonal mitochondrial transport in response to changes in extracellular glucose (Pekkurnaz et al., 2014). Globally, loss of OGT in sensory neurons could disrupt the metabolic homeostasis of the cells if pathways become less sensitive to changes in metabolic flux. In fact, metabolic perturbations associated with mitochondrial dysfunction have long been associated with mechanisms of axonal degeneration and decreased neuronal health (Court and Coleman, 2012). Altogether, it is likely that the observed phenotypes are the result of many altered processes occurring in the neurons. Additional proteomic studies with OGT-knock-out sensory neurons may yield further mechanistic insight into these changes but no individual loss of $O$-GlcNAcylation may prove to be essential to the degeneration. While studies have shown that OGT is essential for survival of mitotic cells in mice (Shafi et al., 2000; O'Donnell et al., 2004; Levine and Walker, 2016), possibly due to the role of $O$-GlcNAcylation in the cell cycle and cytokinesis (Slawson et al., 2005), this is the first study to demonstrate the importance of the modification in the maintenance and ultimate survival of postmitotic neurons. The severity of the phenotype furthers our appreciation of $\mathrm{O}$-GlcNAc signaling as crucial and ubiquitous in regulating cellular functions.

The effects of loss of OGT on thermal sensitivity were clearer than on mechanical sensitivity at both $10-11$ and 30-31 weeks. This is consistent with the fact that Nav1.8 expression is predominantly in small-diameter neurons responsible for nociception and thermal sensation (Agarwal et al., 2004). However, Nav1.8Cre expression is not strictly limited to C-fiber neurons. Cre expression in a small population of A-fiber neurons, as well as the loss of OGT in mechanosensitive $\mathrm{C}$ fibers, could account for the mild hyposensitivity of Nav1.8-Ogt knock-out mice in the von Frey assay.

In Nav1.8-Ogt knock-out mice, both loss of epidermal innervation and loss of cell bodies were observed early in development but also seemed to progress as the animals aged. In particular, significant decreases in nerve fiber endings were measured in adult Nav1.8-Ogt knock-out mice at a stage when control animal nerve fiber counts remained stable. Using the inducible brn3a$\mathrm{CreER}^{T 2}$ driver clarified that loss of OGT in the adult decreases the survival of adult neurons. In the brn $3 a-O g t$ knock-out mice 2 weeks after tamoxifen treatment, there was already a decrease in nerve fiber density in the paw (Fig. 7B), although DRG cell-body counts remained the same as those in controls (Fig. 7D). By 4 weeks after treatment, epidermal innervation was significantly further decreased (Fig. $7 B$ ), whereas there was only a modest decrease in cell-body counts (Fig. 7D). Together, this suggests that loss of OGT results in an axonal dieback phenotype first, which then progresses to overall death of the neuron.

Interestingly, thermal sensitivity as measured by the thermal place preference assay was only mildly affected in brn3a-Ogt knock-out animals by 4 weeks after treatment (Fig. $7 E, F$ ), despite significant loss of epidermal innervation. This is similar to what was observed in the Nav1.8-Ogt knock-out mice, which did not exhibit very severe behavioral deficits at 10 weeks of age 
(Fig. 3) despite severe loss of nerve fibers at that time (Fig. 4A,B). It is likely that under normal circumstances, there are far more nerve fibers in the skin than are needed for proper sensation of the stimuli used in the tests, so that a partial reduction in nerve endings would not immediately translate to a functional deficit. Additionally, more nerve fibers may be present in the skin than can be visualized by immunostaining, which is dependent on the penetrance and specificity of the PGP9.5 antibody in the tissue. Nonetheless, we observed in our study that a severe decrease in nerve fiber density in the skin is necessary before behavioral consequences can be detected.

In addition to hyposensitivity to thermal and mechanical stimuli, Nav1.8-Ogt knock-out animals weighed less than controls (Fig. 2A). Because Nav1.8 is expressed in vagal sensory neurons that innervate the viscera (Gautron et al., 2011), altered innervation of organs, such as the pancreas and gut, could be affecting the overall metabolism of the animal and contributing to the weight and glucose tolerance phenotypes. Increased glucose tolerance signals a possible increase in insulin secretion and/or an increased sensitivity of target tissues to circulating insulin, such that glucose is cleared from the blood faster (Bowe et al., 2014). Impaired glucose tolerance is associated with obesity and diabetes (Nathan et al., 2007), and therefore differences in glucose metabolism may be related to differences in weight here as well. An additional possibility is that taste and olfactory sensation could be altered in these mice, which would affect feeding. Future experiments examining visceral nerve fibers, feeding intake, and other metabolic parameters, such as plasma insulin levels, could elucidate the relationship of sensory neuron OGT and weight gain.

Differences in axons were not only observed in vivo but also in cultured DRG neurons. OGT-knock-out neurons exhibited less axonal outgrowth in vitro compared with control neurons (Fig. 6). This demonstrates that loss of OGT has cell-autonomous effects that alter growth and morphology, which may affect the overall health of the neuron. However, the decrease in outgrowth observed here contrasts with results from previous studies in which decreased $O$-GlcNAcylation increased axon length in cultures of embryonic mouse cortical neurons (Rexach et al., 2012) and increased axon branching in embryonic chicken forebrain neurons (Francisco et al., 2009). Differences in the neuronal subtypes and developmental stages, which can also affect baseline morphology and therefore the analytical methods, may explain the differences. The previous studies also use in vitro methods of decreasing $\mathrm{O}$-GlcNAcylation, such as Cre expression in dissociated Ogt-floxed neurons and overexpression of $O$-GlcNAcase, the enzyme that removes the $O$-GlcNAc modification from proteins. These methods may not have achieved the same extent of enzymatic loss as knock-out of the gene in vivo.

We hypothesized that the peripheral nervous system might be particularly sensitive to metabolic perturbations and that the absence of OGT would therefore have a great effect. A recent study deleted Ogt in Schwann cells in mice and found that the mice developed neuropathy characterized by progressive myelin loss, axonal loss, and motor and sensory nerve dysfunction (Kim et al., 2016). These findings demonstrate the importance of OGT in maintaining normal myelin and healthy axons and provide a counterpart to our study in sensory neurons. Together, the studies show that $O$-GlcNAcylation has crucial roles in the health and proper functioning of the peripheral nervous system.

In summary, we find that OGT is essential for sensory neuron survival and target innervation. It is therefore possible that altered $\mathrm{O}$-GlcNAc signaling in neurons contributes to the develop- ment of neuropathy in different disease states. Given the role of OGT in metabolic sensing, this is particularly relevant to diabetic neuropathy. This common complication of diabetes often occurs in patients with uncontrolled high blood-glucose levels and primarily manifests as an axonopathy, though a few studies have demonstrated the presence of neuron death in rodent models of diabetic neuropathy as well (Vincent et al., 2002; Ziegler, 2006; Callaghan et al., 2012). It is conceivable then that, under diabetic conditions, $\mathrm{O}$-GlcNAc signaling becomes misregulated, disrupts cellular processes, and eventually causes axonal degeneration. Additionally, the effects of OGT knock-out on neuronal survival may apply to CNS neurons as well, and long-term studies that alter $O$-GlcNAc signaling in the brain may encounter such consequences as synapse loss, axonal degeneration, and neuron loss.

\section{References}

Agarwal N, Offermanns S, Kuner R (2004) Conditional gene deletion in primary nociceptive neurons of trigeminal ganglia and dorsal root ganglia. Genesis 38:122-129. CrossRef Medline

Bond MR, Hanover JA (2015) A little sugar goes a long way: the cell biology of O-GlcNAc. J Cell Biol 208:869-880. CrossRef Medline

Bowe JE, Franklin ZJ, Hauge-Evans AC, King AJ, Persaud SJ, Jones PM (2014) Metabolic phenotyping guidelines: assessing glucose homeostasis in rodent models. J Endocrinol 222:G13-G25. CrossRef Medline

Callaghan BC, Cheng HT, Stables CL, Smith AL, Feldman EL (2012) Diabetic neuropathy: clinical manifestations and current treatments. Lancet Neurol 11:521-534. CrossRef Medline

Catala M, Kubis N (2013) Gross anatomy and development of the peripheral nervous system. Handb Clin Neurol 115:29-41. CrossRef Medline

Court FA, Coleman MP (2012) Mitochondria as a central sensor for axonal degenerative stimuli. Trends Neurosci 35:364-372. CrossRef Medline

Dentin R, Hedrick S, Xie J, Yates J3rd, Montminy M (2008) Hepatic glucose sensing via the CREB coactivator CRTC2. Science 319:1402-1405. CrossRef Medline

Durning SP, Flanagan-Steet H, Prasad N, Wells L (2016) O-linked $\beta-N$ acetylglucosamine (O-GlcNAc) acts as a glucose sensor to epigenetically regulate the insulin gene in pancreatic beta cells. J Biol Chem 291:21072118. CrossRef Medline

Francisco H, Kollins K, Varghis N, Vocadlo D, Vosseller K, Gallo G (2009) O-GlcNAc post-translational modifications regulate the entry of neurons into an axon branching program. Dev Neurobiol 69:162-173. CrossRef Medline

Gao Y, Wells L, Comer FI, Parker GJ, Hart GW (2001) Dynamic $O$-glycosylation of nuclear and cytosolic proteins. Cloning and characterization of a neutral, cytosolic $\beta$ - $N$-acetylglucosaminidase from human brain. J Biol Chem 276:9838-9845. CrossRef Medline

Gautron L, Sakata I, Udit S, Zigman JM, Wood JN, Elmquist JK (2011) Genetic tracing of Nav1.8-expressing vagal afferents in the mouse. J Comp Neurol 519:3085-3101. CrossRef Medline

Haltiwanger RS, Blomberg MA, Hart GW (1992) Glycosylation of nuclear and cytoplasmic proteins. Purification and characterization of a uridine diphospho- $N$-acetylglucosamine: polypeptide $\beta$ - $N$-acetylglucosaminyltransferase. J Biol Chem 267:9005-9013. Medline

Hart GW, Housley MP, Slawson C (2007) Cycling of O-linked $\beta-N$ acetylglucosamine on nucleocytoplasmic proteins. Nature 446:10171022. CrossRef Medline

Kim S, Maynard JC, Sasaki Y, Strickland A, Sherman DL, Brophy PJ, Burlingame AL, Milbrandt J (2016) Schwann cell O-GlcNAc glycosylation is required for myelin maintenance and axon integrity. J Neurosci 36:96339646. CrossRef Medline

Kreppel LK, Blomberg MA, Hart GW (1997) Dynamic glycosylation of nuclear and cytosolic proteins. Cloning and characterization of a unique $O$-GlcNAc transferase with multiple tetratricopeptide repeats. J Biol Chem 272:9308-9315. CrossRef Medline

Lagerlöf O, Slocomb JE, Hong I, Aponte Y, Blackshaw S, Hart GW, Huganir RL (2016) The nutrient sensor OGT in PVN neurons regulates feeding. Science 351:1293-1296. CrossRef Medline

Lazarus BD, Love DC, Hanover JA (2009) O-GlcNAc cycling: implications for neurodegenerative disorders. Int J Biochem Cell Biol 41:2134-2146. CrossRef Medline 
Levine ZG, Walker S (2016) The biochemistry of O-GlcNAc transferase: which functions make it essential in mammalian cells? Annu Rev Biochem 85:631-657. CrossRef Medline

Ma J, Hart GW (2014) O-GlcNAc profiling: from proteins to proteomes. Clin Proteomics 11:8. CrossRef Medline

Nathan DM, Davidson MB, DeFronzo RA, Heine RJ, Henry RR, Pratley R, Zinman B, Zinman B (2007) Impaired fasting glucose and impaired glucose tolerance: implications for care. Diabetes Care 30:753-759. CrossRef Medline

O'Donnell N, Zachara NE, Hart GW, Marth JD (2004) Ogt-dependent $\mathrm{X}$-chromosome-linked protein glycosylation is a requisite modification in somatic cell function and embryo viability. Mol Cell Biol 24:16801690. CrossRef Medline

O’Donovan KJ, Ma K, Guo H, Wang C, Sun F, Han SB, Kim H, Wong JK, Charron J, Zou H, Son YJ, He Z, Zhong J (2014) B-RAF kinase drives developmental axon growth and promotes axon regeneration in the injured mature CNS. J Exp Med 211:801-814. CrossRef Medline

Pekkurnaz G, Trinidad JC, Wang X, Kong D, Schwarz TL (2014) Glucose regulates mitochondrial motility via Milton modification by $\mathrm{O}$-GlcNAc transferase. Cell 158:54-68. CrossRef Medline

Rexach JE, Clark PM, Mason DE, Neve RL, Peters EC, Hsieh-Wilson LC (2012) Dynamic O-GlcNAc modification regulates CREB-mediated gene expression and memory formation. Nat Chem Biol 8:253-261. CrossRef Medline

Ruan HB, Han X, Li MD, Singh JP, Qian K, Azarhoush S, Zhao L, Bennett AM, Samuel VT, Wu J, Yates JR 3rd, Yang X (2012) O-GlcNAc transferase/host cell factor $\mathrm{C} 1$ complex regulates gluconeogenesis by modulating PGC- $1 \alpha$ stability. Cell Metab 16:226-237. CrossRef Medline

Ruan HB, Singh JP, Li MD, Wu J, Yang X (2013) Cracking the O-GlcNAc code in metabolism. Trends Endocrinol Metab 24:301-309. CrossRef Medline

Ruan HB, Dietrich MO, Liu ZW, Zimmer MR, Li MD, Singh JP, Zhang K, Yin $\mathrm{R}, \mathrm{Wu}$ J, Horvath TL, Yang X (2014) O-GlcNAc transferase enables AgRP neurons to suppress browning of white fat. Cell 159:306-317. CrossRef Medline

Shafi R, Iyer SP, Ellies LG, O’Donnell N, Marek KW, Chui D, Hart GW, Marth JD (2000) The O-GlcNAc transferase gene resides on the $\mathrm{X}$ chromosome and is essential for embryonic stem cell viability and mouse ontogeny. Proc Natl Acad Sci U S A 97:5735-5739. CrossRef Medline

Shields SD, Ahn HS, Yang Y, Han C, Seal RP, Wood JN, Waxman SG, Dib-Hajj SD (2012) Nav1.8 expression is not restricted to nociceptors in mouse peripheral nervous system. Pain 153:2017-2030. CrossRef Medline
Slawson C, Zachara NE, Vosseller K, Cheung WD, Lane MD, Hart GW (2005) Perturbations in $O$-linked $\beta$ - $N$-acetylglucosamine protein modification cause severe defects in mitotic progression and cytokinesis. J Biol Chem 280:32944-32956. CrossRef Medline

Soesanto Y, Luo B, Parker G, Jones D, Cooksey RC, McClain DA (2011) Pleiotropic and age-dependent effects of decreased protein modification by $O$-linked $N$-acetylglucosamine on pancreatic $\beta$-cell function and vascularization. J Biol Chem 286:26118-26126. CrossRef Medline

Stefanini M, De Martino C, Zamboni L (1967) Fixation of ejaculated spermatozoa for electron microscopy. Nature 216:173-174. CrossRef Medline

Tallent MK, Varghis N, Skorobogatko Y, Hernandez-Cuebas L, Whelan K, Vocadlo DJ, Vosseller K (2009) In vivo modulation of O-GlcNAc levels regulates hippocampal synaptic plasticity through interplay with phosphorylation. J Biol Chem 284:174-181. CrossRef Medline

Tomlinson DR, Gardiner NJ (2008) Glucose neurotoxicity. Nat Rev Neurosci 9:36-45. CrossRef Medline

Trinidad JC, Barkan DT, Gulledge BF, Thalhammer A, Sali A, Schoepfer R, Burlingame AL (2012) Global identification and characterization of both $O$-GlcNAcylation and phosphorylation at the murine synapse. Mol Cell Proteomics 11:215-229. CrossRef Medline

Vincent AM, Brownlee M, Russell JW (2002) Oxidative stress and programmed cell death in diabetic neuropathy. Ann N Y Acad Sci 959:368383. CrossRef Medline

Wani WY, Chatham JC, Darley-Usmar V, McMahon LL, Zhang J (2016) O-GlcNAcylation and neurodegeneration. Brain Res Bull pii:S03619230(16)30171-X. CrossRef Medline

Whelan SA, Dias WB, Thiruneelakantapillai L, Lane MD, Hart GW (2010) Regulation of insulin receptor substrate 1 (IRS-1)/AKT kinase-mediated insulin signaling by $O$-linked $\beta$ - $N$-acetylglucosamine in $3 \mathrm{~T} 3-\mathrm{L} 1$ adipocytes. J Biol Chem 285:5204-5211. CrossRef Medline

Yang X, Ongusaha PP, Miles PD, Havstad JC, Zhang F, So WV, Kudlow JE, Michell RH, Olefsky JM, Field SJ, Evans RM (2008) Phosphoinositide signalling links $O$-GlcNAc transferase to insulin resistance. Nature 451: 964-969. CrossRef Medline

Zachara NE, Hart GW (2004) O-GlcNAc a sensor of cellular state: the role of nucleocytoplasmic glycosylation in modulating cellular function in response to nutrition and stress. Biochim Biophys Acta 1673:13-28. CrossRef Medline

Ziegler D (2006) Treatment of diabetic polyneuropathy: update 2006. Ann N Y Acad Sci 1084:250-266. CrossRef Medline

Zochodne DW (2008) Diabetic polyneuropathy: an update. Curr Opin Neurol 21:527-533. CrossRef Medline 